\title{
The effect of inspiratory muscle training on the quality of life, immune response, inspiratory and lower limb muscle strength of older adults: a randomized controlled trial
}

\author{
Adriano Florencio Vilaça' ${ }^{1 D}$ \\ Bárbara Cristina de Souza Pedrosa ${ }^{1}$ (ID \\ Thamara Cunha Nascimento Amaral' (ID \\ Maria do Amparo Andrade² $\mathbb{D}$ \\ Célia Maria Machado Barbosa de Castro ${ }^{3}$ (D) \\ Eduardo Eriko Tenório de França ${ }^{4}$ (D)
}

Abstract

Objective: To evaluate the impact of inspiratory muscle training (IMT) on the quality of life, immune response, inspiratory and lower limb muscle strength of older adults. Method: A randomized clinical trial was conducted with 30 institutionalized older adults. They were allocated into two groups: the IMT group $(n=15)$, which underwent IMT with PowerBreathe Classic, using a load of $60 \%$ of maximal inspiratory pressure (MIP). This was performed using a 30 repetition protocol, three times a week, for six weeks. The second group was the control group $(n=15)$ which did not perform any type of therapeutic intervention. In both groups, MIP, lower limb strength by sit-up test, quality of life by the SF-36 questionnaire and C-reactive protein (CRP) were evaluated. Results: The results demonstrated the homogeneity between the groups regarding the demographic and clinical variables. The IMT group showed an increase in the variation of MIP $(9.20 \pm 7.36 \mathrm{cmH} 2 \mathrm{O})$ compared to the control $(0.93 \pm 8.79 \mathrm{cmH} 2 \mathrm{O})$. Improvement was also observed in the sitting and standing test $(p<0.05)$ (Tukey Test) in the difference between the values before and after the IMT. In terms of quality of life, two of the eight SF-36 domains were influenced by the IMT, namely: functional capacity and limitations due to physical factors. There were no changes in CRP in either group. Conclusion: IMT improved the inspiratory muscle strength, lower limb strength and quality of life of institutionalized older adults. These findings reinforce the contribution of this therapy to reducing the deleterious effects of aging.

\footnotetext{
Universidade Federal de Pernambuco, Departamento de Biologia Aplicada a Saúde. Recife, PE, Brasil.

Universidade Federal de Pernambuco, Departamento de Fisioterapia. Recife, PE, Brasil.

Universidade Federal de Pernambuco, Departamento de Medicina Tropical. Recife, PE, Brasil.

Universidade Federal da Paraíba, Programa de Pós-graduação em Fisioterapia. João Pessoa, PB, Brasil.
}

Funding:: Fundação de Amparo à Ciência e Tecnologia do Estado de Pernambuco (FACEPE), sob o processo de $\mathrm{N}^{\circ}$ IBPG - 1073-4.08/16.

The authors declare there are no conflicts of interest in relation to the present study.

Correspondence

Eduardo Eriko Tenório de França

edueriko@hotmail.com

\author{
Keywords: Aging. \\ Respiratory Muscle Training. \\ Immune Response.
}




\section{INTRODUCTION}

Aging is a natural process and brings with it a series of adaptations and changes to various bodily systems. The alterations to the immune system that arise from aging are known as immunosenescence and cause physiological changes, resulting in an increased incidence of infectious diseases, morbidity and mortality in older adults ${ }^{1,2}$.

One of the main consequences of the aging process is the decline in overall muscle strength, which has a direct impact on functional capacity and the performance of activities of daily living among this population group. The reduction in muscle mass and strength does not depend on the presence of diseases, but is accentuated in older adults affected by diseases that limit their mobility ${ }^{3}$. Respiratory muscle weakness alone is a major limiting factor for the deterioration of physical fitness, as it triggers changes in lung function, reduced muscle strength and dyspnoea ${ }^{4}$.

It has previously been reported that physical exercise in the older population generates a series of benefits, such as increased functional capacity, the reduced incidence of infections, improved cardiovascular conditioning, and enhanced muscle fiber and quality of $\operatorname{life}^{2}$. In general, regular physical exercise induces a local and systemic antiinflammatory state in the body, enabling adaptations and protection against chronic inflammatory pathologies $^{5}$

Aerobic physical activity generates systemic benefits, including gains in respiratory muscle strength. Inspiratory muscle training (IMT) has been shown to have a direct relationship with the functional autonomy of older adults ${ }^{3,6}$. The gain in respiratory muscle strength improves the physical performance of such individuals, increasing maximum oxygen consumption during effort and reducing muscle fatigue. This results in an improvement in muscle quality and a reduction in the deleterious effects on the respiratory muscles caused by sarcopenia. The functional capacity of older adults is therefore enhanced, resulting in greater independence in activities of daily living with an improvement in quality of life ${ }^{7,8}$.
Physical activity, through aerobic training, is established as the main non-medication based treatment for curbing the effects of the inflammatory processes common to aging. A new trend for treating this specific population is using devices capable of generating inspiratory load, bringing benefits to the pulmonary system. IMT can be performed with several types of devices, where the individual in training performs forced inspirations against an imposed load, aiming at improving lung function, inspiratory muscle strength and thoracoabdominal mobility, and is considered an efficient and safe physiotherapeutic resource $e^{6,9,10}$.

With global population aging, the number of active older adults in society has progressively increased, making the physiological alterations of this population of particular interest ${ }^{11,12}$. It is believed that IMT contributes to minimizing the damage caused by aging, reducing inflammatory markers and increasing respiratory muscle strength, functionality and quality of life. The present study therefore aimed to assess the impact of IMT on respiratory strength, lower limb strength, immune response and quality of life in older adults.

\section{METHOD}

A controlled and randomized clinical trial was performed involving participants living in four Long-Term Care Facilities (LTCFs) in the city of Recife, Pernambuco, Brazil, who previously signed Informed Consent Forms (ICF) to confirm their participation in the study. The study protocol was published in the Brazilian Registry of Clinical Trials (or ReBEC), under number RBR-7g4dhr and met the CONSORT guidelines for clinical trials. This study was approved by the Ethics and Research Committee of the Health Sciences Center of the Universidade Federal de Pernambuco (the Federal University of Pernambuco) under decision number 2.264.422 and complied with Resolution $n^{\circ}$ 466/2012 and $\mathrm{n}^{\circ} 510 / 2016$.

The sample calculation was performed using the WinPepi program (PEPI-for-Windows) based on the following criteria: 95\% confidence interval and a sampling error of five percentage points. Based on 
the total number of 40 older adults who underwent IMT in a study by Iranzo et al. ${ }^{13}$, a standard deviation of seven percentage points and a sample loss of $30 \%$ in the same study, a minimum sample of 13 older adults was calculated.

As inclusion criteria, adults over the age of 65 , of both sexes, residents of the LTCFs, who were healthy and agreed to participate in the research were included in the study. Older adults were excluded from the study if they did not understand any of the steps of the proposed protocols, had a body mass index above $35 \mathrm{~mL} / \mathrm{kg}^{2}$ or had some degree of orthopedic or neurological limitation that made it impossible to perform the tests. Even after randomization and the start of the research protocol, some participants were excluded from the study if they had any of the following criteria: changes in LTCF, missing two consecutive sessions or five sessions in total over the six weeks, suffered from a disease that prevented the training from being carried out or expressed a willingness to discontinue the study.

C-reactive protein (CRP) was assessed through the collection of peripheral blood by a qualified nursing professional. Patients eligible for the study underwent venous blood collection before the start of the protocol and after six weeks. The blood collected was distributed in vacuum tubes, identified and taken for CRP analysis in a specialized laboratory.

Inspiratory muscle strength was assessed through maximum inspiratory pressure by the MVD300 digital manometer (GlobalMed), in the sitting position, with a $90^{\circ}$ angle between the torso and the thighs. Participants were instructed on how to perform the maneuver, which was demonstrated in a practical manner by the evaluator. All measurements started from the residual volume to the maximum inspiration of the participant, in a rapid, forced manner, inhaling through a mouthpiece while using a nose clip. In the system applied, a small hole was used to attenuate the interference of the glottis in the measurement. Up to five consecutive maneuvers were performed, three of which were required to be considered acceptable, without leaks and lasting more than two seconds. Of the acceptable maneuvers, at least two were to be reproducible, with values that did not vary from the highest value by more than $10 \%$.
The highest value was used for evaluation criteria. The exact value of the register was measured at the peak pressure of the maneuver. The values were subsequently analyzed and compared with specific reference values for age and $\operatorname{sex}^{14}$.

To assess the strength of the lower limbs, the Sit to Stand Test (SST) was performed. Each participant was positioned in the center of a chair, with their spines erect, feet fully supported on the floor and arms crossed against the chest; they were instructed to perform sitting and standing repetitions, alternating between fully standing and sitting, without the support of their hands. Participants were encouraged to perform as many repetitions as possible over a 30 -second period. The final result was determined by counting the number of times the participant performed the movement of sitting and standing correctly. The number of repetitions, age and sex were considered when predicting a satisfactory test result ${ }^{15}$.

To evaluate quality of life, the Medical Outcomes Study 36-item short-form health survey (SF-36) questionnaire was used. This was applied in the form of an interview, always by the same evaluator, with all participants evaluated in isolation, guaranteeing the confidentiality of their answers. The questions were read by the evaluator as many times as requested and the participant was instructed to select only one of the alternatives presented to them. After the questionnaire was applied, the scores were calculated, where the values of the questions were transformed into scores for eight domains, ranging from 0 to 100 , where $0=$ the worst and $100=$ the best possible status for each domain ${ }^{16}$. As with the other stages of the evaluations, the quality of life questionnaire was carried out before and after the six-week protocol period.

Randomization for participation in the groups was carried out using the web site http://www. randomization.com. Participants were randomized into two groups: the IMT Group, where the six-week IMT protocol was applied, and the control group where only the initial and final evaluations were performed, without any type of physical therapy intervention, over the same time period as the intervention group.

Participants in the IMT group underwent inspiratory muscle training, using an inspiratory 
pressure resistor from the PowerBreathe Classic ${ }^{\circledR}$ series. Participants were instructed to perform forced and rapid inspirations through their mouths and were encouraged to reach their maximum inspiratory capacities $^{17}$. The load used for the IMT was equivalent to $60 \%$ of the maximum inspiratory pressure (MIP), with an adaptation period, where the initial load was $20 \%$ of MIP on the first day, $40 \%$ on the second day and $60 \%$ on the third day until the end of the protocol. Each session consisted of 30 repetitions of consecutive forced inspirations through a mouthpiece connected to the device. Participants used a nose clip while performing the training to avoid any leakage of air that would decrease the effort expended. Initially, the participants were instructed to remain seated in the chair, at a $90^{\circ}$ angle, in an upright and comfortable position. They were advised to perform the 30 maximum inspiration repetitions in a row, although they were allowed to stop to rest, for as brief a time as possible, if necessary. Each inspiratory effort was initiated from the residual volume and the participant was instructed to maximize the inspiratory volume with each repetition. The total training time was six weeks, with three sessions of 30 repetitions performed on alternate days each week: Mondays, Wednesdays and Fridays ${ }^{18}$.

Descriptive analysis of the data obtained was performed, showing the mean and standard deviation for each analyzed variable. The $\mathrm{T}$ test was used to compare the mean and standard deviation of the two groups studied and analysis of variance (ANOVA) was used for the comparative analysis of the parametric data obtained in the evaluation of the treatment effect, with the Tukey test applied for the comparison of the means of the delta values $(\Delta)$ (after confirming the normal distribution of the sample with the Shapiro-Wilk test). For delta calculation, the values obtained in the post-training moment were subtracted from the data obtained in the pretraining moment. ( $\Delta=$ Final - Initial). The level of significance adopted was $5 \%(p<0.05)$. To compare the before and after results each group, the Wilcoxon nonparametric test was used. All conclusions were taken at the 5\% significance level.

\section{RESULTS}

While a total of 54 potential older adult participants met the inclusion criteria, 22 exhibited some of the exclusion criteria and so only 32 individuals were included in the research. However, two participants were unable to complete the training protocol due to presenting a criteria for discontinuing the research. Therefore, only 30 older adults completed the analysis, being distributed as follows: control group ( $\mathrm{n}=15)$, where the participants did not undergo any type of therapy during the six week protocol; and the IMT group ( $\mathrm{n}=15)$, where a protocol for strengthening the inspiratory muscles was performed using the PowerBreathe Classic for six weeks. The order of entry into the groups was made randomly.

Figure 1 shows a flowchart for the selection and allocation of participants in the study.

Table 1 shows the demographic variables of the patients in each of the groups evaluated, control and IMT, shown in mean and standard deviations.

Figure 2 describes the initial and final values of inspiratory muscle strength based on MIP values, as well as the variation between the two after the six weeks of the study protocol. A difference $(p<0.05)$ was observed between the before and after variation values of the IMT group and those of the control group. There was no difference in the MIP values expected for age and sex.

In relation to the SST, there was a difference $(p<0.05)$ in the variation values before and after the IMT. The group that received the training recorded a greater variation in the number of times they sat and stood in 30 seconds than the group without training. Figure 3 shows the behavior and variation in the SST before and after the protocol period.

Figure 4 shows the behavior of the variation in the CRP serum concentration between the groups before and after six weeks. The training protocol did not alter the variation in CRP. 


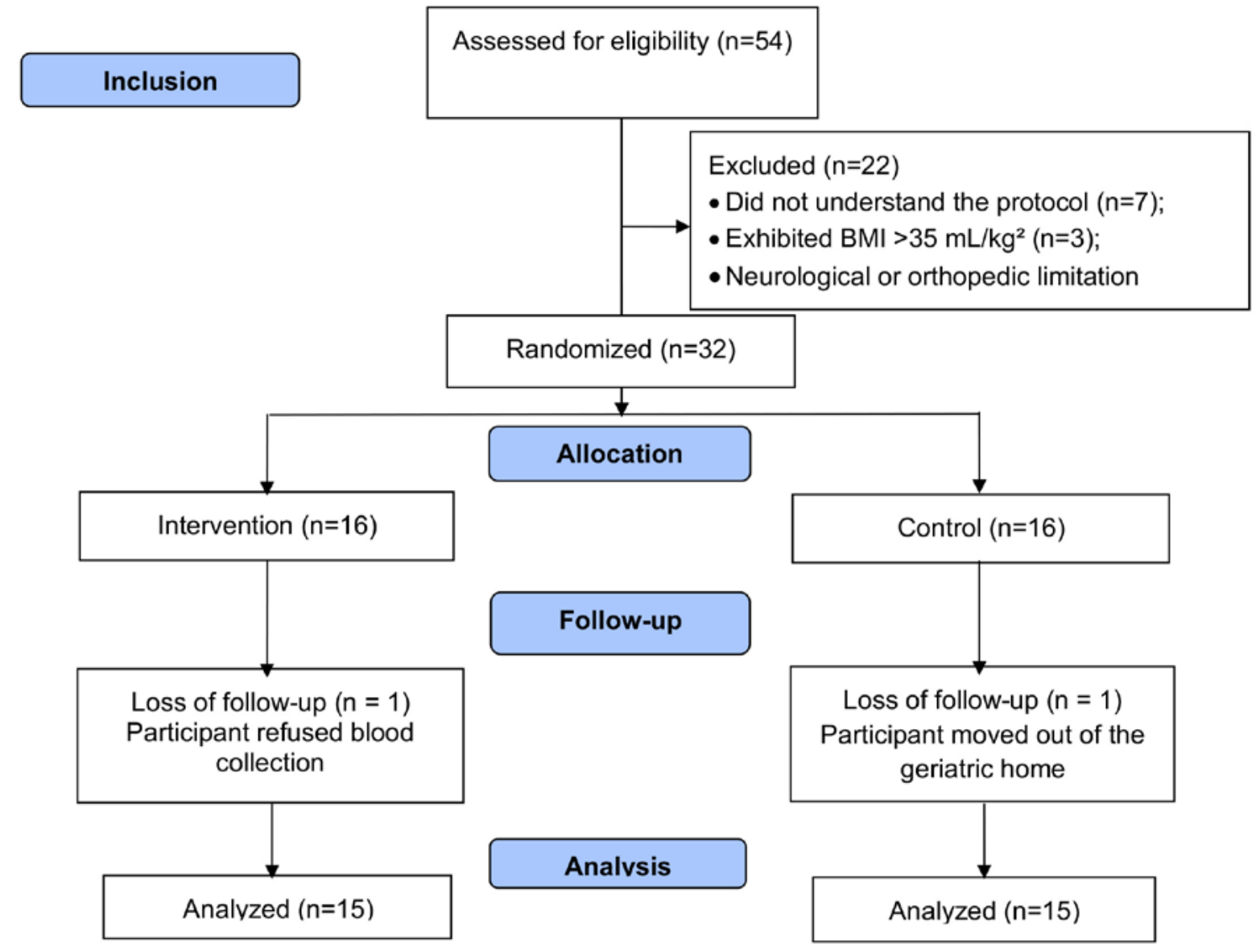

Figure 1. Flowchart of allocation of participants. Pernambuco, Brazil.

Table 1. Mean and standard deviation of age and sex of patients in the studied groups.

\begin{tabular}{llll}
\hline Variables & $\begin{array}{l}\text { Control } \\
(\mathrm{n} \%)\end{array}$ & $\begin{array}{l}\text { IMT } \\
(\mathrm{n} \%)\end{array}$ & $p$ \\
\hline Sex & $13(86.6 \%)$ & $11(73.3 \%)$ & 0.37 \\
Male & $2(13.3 \%)$ & $4(26.6 \%)$ & \\
Female & $76.33 \pm 9.79$ & $80.33 \pm 7.71$ & 0.42 \\
Age (mean $\pm \mathrm{sd})$ &
\end{tabular}

Data expressed as mean \pm standard deviation; Comparison between the two groups, $\mathrm{T}$ test. 


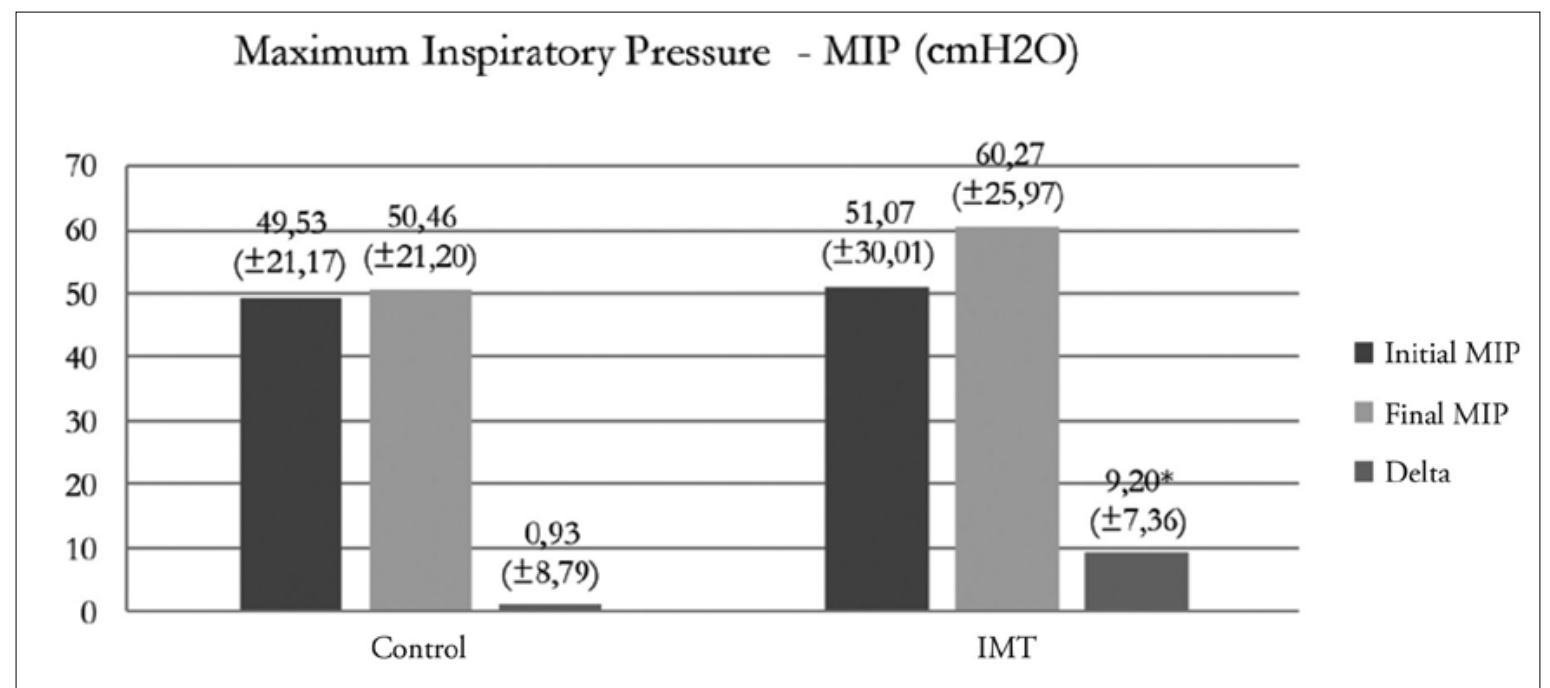

Data expressed as mean \pm standard deviation; Comparison before and after for each group - Tukey test.

Figure 2. Mean and standard deviations of PiMax $(\mathrm{cmH} 2 \mathrm{O})$ obtained during the initial and final evaluation of the control (CON) and inspiratory muscle training (IMT) groups. Pernambuco, Brazil.

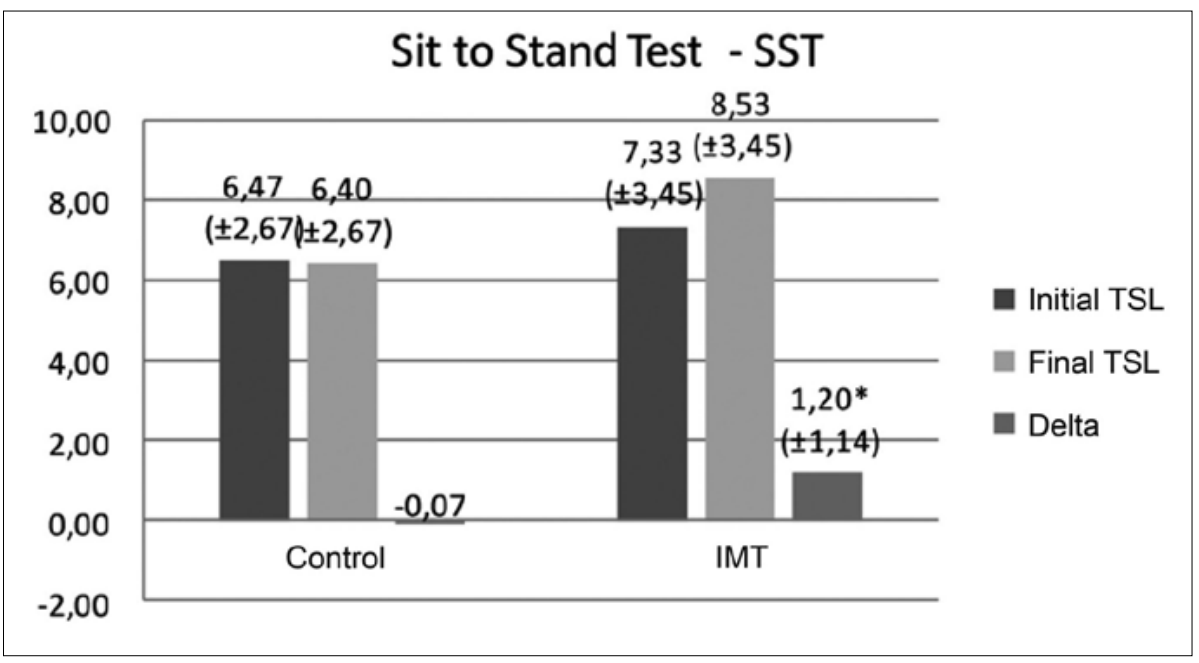

Data expressed as mean \pm standard deviation; Comparison before and after for each group - Tukey test.

Figure 3. SST means obtained during the initial and final evaluation of the control (CON) and inspiratory muscle training (IMT) groups. Pernambuco, Brazil. 


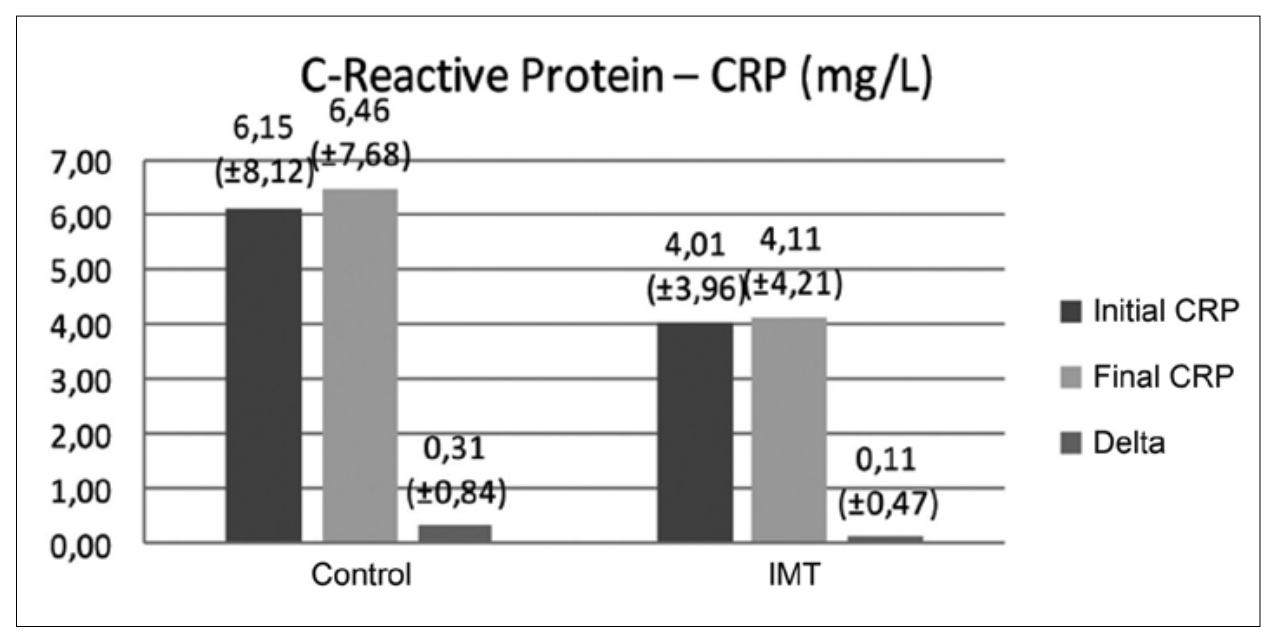

Data expressed as mean \pm standard deviation; Comparison before and after for each group - Tukey test.

Figure 4. CRP measurements obtained during the initial and final evaluation of the Control (CON) and inspiratory muscle training (IMT) groups. Pernambuco, Brazil.

In terms of quality of life, two of the eight domains of the SF-36 were influenced by the training, namely: functional capacity, before $(56.33 \pm 17.78)$ and after $(62.33 \pm 19.54)$ the IMT $(p=0.0009)$, and limitations due to physical aspects, before $(66.00 \pm 31.36)$ and after $(71.00 \pm 29.71)$ the IMT $(p=0.0384)$.

\section{DISCUSSION}

The present study showed that the six-week IMT protocol increased inspiratory muscle strength, an effect noted following the improvement in MIP observed in the trained group in comparison with the control group. The improvement in MIP is in line with most studies that evaluate the effects of IMT in healthy older adults, and is based on the increased motor unit recruitment during the period of muscle training $8,13,16,18$.

In a study carried out by Feriani et al. ${ }^{19}$, gains in respiratory muscle strength were observed in just seven sessions of IMT with a spring resistor device in a group of 16 older women with metabolic syndrome. This study used a load of $30 \%$ of MIP, and each session consisted of 45 minutes of training. In the present study a relatively high load was used, but only 30 repetitions were applied, and in general the participants succeeded in carrying out the training. There is no consensus in literature regarding the load and the number of repetitions used in IMT. It is assumed that low loads for longer periods of time, or a greater number of repetitions, are suitable for improving muscle endurance, while higher loads with fewer repetitions are suitable for increasing muscle strength ${ }^{16,18}$.

A gain in respiratory muscle strength was also observed in the study by Pascotini et al. ${ }^{20}$, this time with a daily protocol over 12 consecutive days. Flow and volume incentive spirometry devices were used, and both were able to improve the strength outcome. On average, three sets of 12 repetitions per day were performed. This protocol can be used mainly by individuals with good cognitive ability who can train without supervision.

It is possible that the specific exercise of the inspiratory musculature leads to changes in the structure of these muscles, with an increase in the synthesis of the contractile proteins actin and myosin, generating a greater capacity to generate strength. In addition, conditioning and resistance result in increased levels of oxidative enzymes, lipid reserve, glycogen and number of capillaries. Through the load imposed on these muscles, changes in cellular architecture occur in direct proportion to the stimulus generated, a key factor in curbing the effects of sarcopenia in older adults ${ }^{19,21,22}$. 
An increase in SST performance was observed in the IMT group after six weeks of training. It is known that exercise improves physical fitness in older adults, which is reflected in improved performance in tests of peripheral muscle strength and functionality ${ }^{23}$. The improvement in the final test result when compared to the control group corroborates the work carried out by Fonseca et al. ${ }^{6}$, where institutionalized older adults presented an increase in functional capacity assessed by the 6-minute walk test (6MWT), after undergoing IMT with the use of the volume incentive spirometer for ten weeks. Although this device is not a widely used IMT resource, it can provide a non-linear pressure load that favors the increased recruitment of motor units resulting, in improved inspiratory muscle strength ${ }^{24}$.

In another study evaluating the effects of IMT in patients undergoing dialysis, Silva et al. ${ }^{25}$ found that eight weeks of training with a load of $40 \%$ of IMP were sufficient to improve the distance covered in the 6MWT. Plentz et al. ${ }^{26}$, also observed improvement in the 6MWT and in MIP after 12 weeks of IMT in cardiac patients. Although most studies use the 6MWT to assess functional capacity in older adults, Silva et al. ${ }^{25}$ observed that the SST showed a positive correlation with the 6MWT, proving to be a safe and easy tool for older adults, in addition to being comparable to the 6MWT in predicting functional condition in this population.

The explanation found for the improvement of peripheral muscle strength parameters, even when only the inspiratory muscles are trained, is based on the attenuation of the phenomenon known as metaboreflex. Inspiratory muscle metaboreflex is a response mediated by the sympathetic nervous system, where there is vasoconstriction in the skeletal muscles during exercise, limiting physical performance by reducing blood flow to the active muscles ${ }^{26}$. When the respiratory muscle is conditioned through IMT, there is an increase in oxygen supply to the peripheral muscles during exercise, improving performance and tolerance ${ }^{27-29}$.

In the present study, the CRP levels remained constant after the six-week period, both in the IMT group and the control group. In literature, no studies were found that associated breathing exercises with serum protein concentration. In a study carried out by Agostinis-Sobrinho et al. ${ }^{30}$, the association between physical activity and CRP was evaluated in 386 adolescents, and no correlation between the variables was observed, with the age group studied and the absence of reference values in this population possible justifications. In a study conducted with adults aged between 40 and 70 years of age with metabolic syndrome, it was observed that the practice of weight training and walking for one hour and thirty minutes, three times a week, for 12 weeks, was sufficient to reduce CRP levels compared to baseline ${ }^{31}$.

Mills et al. ${ }^{18}$, meanwhile, submitted 17 individuals to an IMT program for eight weeks and, although MIP values increased at the end of the training period, no changes in the concentration of inflammatory cytokines in the blood were recorded. This result can be justified by the fact that the respiratory muscle mass represents only approximately 3\% of total body weight, and the increase in its workload is not sufficient to alter the systemic concentration of cytokines and, consequently, of CRP. It is important to note that although CRP is the main inflammatory marker used today, conditions such as bacterial or viral infections can increase protein synthesis, in an acute manner, changing its serum value in blood analysis ${ }^{32}$.

The improvement in quality of life with the practice of physical activity is clearly established in the literature. Scherer et al. ${ }^{33}$, observed an improvement in quality of life, assessed through the SF-12 questionnaire, after an IMT protocol of eight weeks, with training five times a week, in patients with COPD. On the other hand, Gomes et al. ${ }^{34}$, in a study that evaluated respiratory muscle strength, quality of life, degree of dependence and functional capacity in institutionalized older adults, found no correlations between these variables. The justification for these results was attributed to the transversal character of the study.

In isolation, IMT did not result in an improvement in the majority of the domains of the SF-36 quality of life questionnaire in the present study. However, the two domains that exhibited improvement in the group that received the IMT were related to functionality: functional capacity and physical limitations. The older adults reported through the 
questionnaire that they had improved in these aspects over the six weeks of training, that is, they were able to perform more activities of daily living. It is likely that the improvement in respiratory muscle conditioning reduced the negative effect of the metaboreflex in these individuals, causing them to have fewer episodes of physical limitation ${ }^{6,16,27}$.

It should be noted that the profile of the studied population refers only to institutionalized older adults, which may be directly related to the findings of the study. Although LTCFs are appropriate care environments for this population, it is possible that progressive muscle loss occurs in comparison to the population of the same age group that maintains more active lifestyle habits. Often the environment of these facilities does not offer sufficient incentives to avoid a sedentary lifestyle, accentuating sarcopenia ${ }^{35}$.

From the results obtained, it is clear that for healthy older adults IMT, if performed regularly, can contribute not only to improving the strength of the inspiratory muscles, but is related to peripheral muscle strength and, consequently, to improvements in the quality of life of this population, representing a safe and effective practice. As limitations of the study, the fact that all participants are institutionalized older adults, as well as the small sample size, may have interfered with the final results. Another important

\section{REFERENCES}

1. Brito CJ, Volp ACP, Nóbrega OT, Silva Júnior FL, Mendes EL, Roas AFCM, et al. Exercício físico como fator de prevenção aos processos inflamatórios decorrentes do envelhecimento. Motriz. 2011;17(3):544-55.

2. Santiago LAM, Lima Neto LG, Pereira GB, Leite RD, Mostarda CT, Monzani JOB, et al. Effects of resistance training on immunoinflamatory response, TNF-Alpha Gene expression, and body composition in eldery women. J Aging Res. 2018;2018: 1-10.

3. Rodrigues GD, Gurgel JL, Gonçalves TR, Soares PPS. Inspiratory muscle training improves physical performance and cardiac autonomic modulation in older women. Eur J Appl Physiol. 2018;118(6):1143-52. negative factor was the use of C-reactive protein as a marker in the evaluation of immune response, since other factors may be determinants for changes in the serum level of this protein.

\section{CONCLUSION}

In view of the results presented, we can conclude that six weeks of inspiratory muscle training was able to improve inspiratory muscle strength, increase the strength of the lower limb muscles through the Sit to Stand Test and improve the functional capacity and limitations by physical factors domains of the SF-36 quality of life questionnaire. These findings reinforce the contribution of this therapy in reducing the harmful effects of aging.

No significant changes in C-reactive protein were found. Although there was no protective effect against inflammation as expected, it can be said that inspiratory muscle training did not generate any new or harmful inflammatory processes in this population, and can be considered a safe procedure. It is suggested that new studies are carried out with different training protocols and a larger population, thus contributing to a better understanding of the real needs of this group.

Edited by: Ana Carolina Lima Cavaletti

4. Alvarenga GM, Charkovski AC, Santos LK, Silva MAB, Tomaz GO, Gamba HR. The influence of inspiratory muscle training combined with Pilates method on lung function in eldery women: a randomized controlled Trial. Clinics. 2018;73:e356 [10p.].

5. Silva FOC, Macedo DV. Exercício físico, processo inflamatório e adaptação: uma visão geral. Rev Bras Cineantropon Desempenho Hum 2011;13(4):320-8.

6. Fonseca MA, Cader AS, Dantas EHM, Bacelar SC, Da Silva EB, Leal SMO. Programas de treinamento muscular respiratório: impacto na autonomia funcional de idosos. Rev Assoc Méd Bras. 2010;56(6):642-8.

7. Illi SK, Held U, Frank I, Spengler CM. Effect of respiratory muscle training on exercise performance in healthy individuals: a systematic review and metaAnalysis. Sports Med. 2012;42(8):707-24. 
8. Silva MS, Ramos LR, Tufik S, Togeiro SM, Lopes GS. Influence of Inspiratory Muscle Training on Changes in Fasting Hyperglycemia in the Older Adult: The Epidoso Project. J Diab Sci Technol. 2015;3(2):1-5.

9. Fragoso CAV, Beavers DP, Anton SD, Liu CK, McDermott MM, Newman AB, et al. Effect of Structured Physical Activity on Respiratory Outcomes in Sedentary Elders With Mobility Limitations. J Am Geriatr Soc. 2016;64(3):501-9.

10. Göhl O, Walker DJ, Walterspacher S, Langer D, Spengler CM, Wanke T, et al. Respiratory Muscle Training: State of the Art. Pneumologie. 2016;70:37-48.

11. Seixas MB, Almeida LB, Trevizan PF, Martinez DG, Laterza MC, Vanderlei LCM, et al. Effects of inspiratory muscle training in older adults. Respir Care. 2019;64(12):1455-60.

12. Ferraro FV, Gavin JP, Wainwright T, McConnell A. The effects of 8 weeks of inspiratory muscle training on the balance of healthy older adults: a randomized, double-blind, placebo-controlled study. Physiol Repir. 2019;7(9):e14076 [10 p.].

13. Iranzo MAC, Arnall DA, Camacho CI, Tomás JM, Meléndez JC. Physiotherapy Intervention for Preventing the Respiratory Muscle Deterioration in Institutionalized Older Women With Functional Impairment. Arch Bronconeumol. 2012;49:1-9.

14. Souza RB. Pressões respiratórias estáticas máximas. J Pneumol. 2002;28(Suppl 3):155-65.

15. Rikli R, Jones C. Functional fitness normative scores for community-residing older adults, ages 60-94. J Aging Phys Act. 1999;7(2):162-81.

16. Toscano JJO, Oliveira ACC. Qualidade de vida em idosos com distintos níveis de atividade Física. Rev Bras Med Esporte 2009;15(3):169-73.

17. Esteves F, Santos I, Valeriano J, Tomás MT. Treino de músculos inspiratórios em indivíduos saudáveis: estudo randomizado controlado. Saúde Tecnol. 2016;(15):5-11.

18. Mills DE, Johnson MA, Barnett YA, Smith WHT, Sharpe GR. The effects of inspiratory muscle training in older adults. Med Sci Sports Exerc. 2015(47):691-7.

19. Feriani DJ, Coelho Júnior HJ, Scapini KB, Moraes OA, Mostarda C, Ruberti OM, et al. Effects of inspiratory muscle exercise in the pulmonary function, autonomic modulation, and hemodynamic variables in older women with metabolic syndrome. J Exerc Rehabil. 2017;13(2):218-26.

20. Pascotini FS, Ramos MC, Silva AMV, Trevisan ME. Espirometria de incentivo a volume versus a fluxo sobre parâmetros respiratórios em idosos. Fisioter Pesqui. 2013;20(4):355-60.
21. Takaema DG, Ling CHY, Kurrle SE, Cameron ID, Meskers CGM, Blauw GJ, et al. Temporal relationship between handgrip strength and cognitive performance in oldest old people. Age Ageing. 2012;41:506-12.

22. Iranzo MAC, Arnall DA, Camacho CI, Tomás JM. Effects of inspiratory muscle training and yoga breathing exercises on respiratory muscle function in institutionalized frail older adults: a randomized controlled trial. J Geriatr Phys Ther. 2014;37:65-75.

23. Correia CS, Moraes KCM, Lacerda FC, Radaelli R, Gaya AR, Pinto RS. Avaliação funcional em idosas: uma proposta metodológica. Rev Bras Cineantropom Desempenho Hum. 2013;15(6):745-53.

24. Ferreira CB, Teixeira PS, Santos GA, Maya ATD, Brasil PA, Souza VC, et al. Effects of a 12-week exercise training program on physical function in institutionalized frail eldery. J Aging Res. 2018:1-9.

25. Silva VG, Amaral C, Monteiro MB, Nascimento DM, Boschetti JR. Efeitos do treinamento muscular inspiratório nos pacientes em hemodiálise. J Bras Nefrol 2011;33(1):62-8.

26. Plentz RDM, Sbruzzi G, Ribeiro RA, Ferreira JB, Lago PD. Inspiratory muscle training in patients with heart failure: meta-analysis of randomized trials. Arq Bras Cardiol. 2012;99(2):762-71.

27. Callegaro CC, Ribeiro JP, Tan CO, Taylor JA. Attenuated inspiratory muscle metaboreflex in endurance-trained individuals. Respir Physiol Neurobiol. 2011;177:24-9.

28. Archiza B, Andaku BK, Caruso FCR, Bonjorno Jr JC, Oliveira CR, Ricci PA. Effects of inspiratory muscle training in professional women football players: a randomized sham-controlled trial. J Sports Sci. 2017;36(5):1-10.

29. Moreno AM, Toledo-Arruda ACT, Lima JS, Duarte CS, Villacorta H, Nóbrega ACL. Inspiratory muscle training improves intercostal and forearm muscle oxygenation in patients with chronic heart failure: evidence of the origin of the respiratory metaboreflex. J Card Fail. 2017;23(9):672-9.

30. Agostinis-Sobrinho C, Moreira C, Mota J, Santos R. C-reactive protein, physical activity and cardiorespiratory fitness in Portuguese adolescents: a cross-sectional study. Public Health Rep. 2015;31(9):1-9.

31. Santos RRS, Farinha JB, Azambuja CR, Santos DL. Efeitos do treinamento combinado sobre a proteína C-reativa ultrassensível em indivíduos com síndrome metabólica. ConScientiae Saúde. 2014;13(2):179-86. 
32. Allawi AAD. Malnutrition, inflamation and atherosclerosis (MIA syndrome) in patients with end stage renal disease on maintenance hemodialysis (a single centre experience). Diabetes Metab Syndr. 2018:12(2):91-7.

33. Scherer TA, Spengler CM, Owassapian D, Imhof E, Boltellier U. Respiratory muscle endurance training in chronic obstructive pulmonary disease. Am J Resp Crit Care Med. 2000;162(5):1709-14.
34. Gomes AD, Silva JF, Silva JA, Fréz AR, Mora CTR, Riedi C. Correlação da força muscular respiratória com a qualidade de vida e capacidade funcional de idosos institucionalizados. Rev Bras Qual Vida. 2014;6(1):38-45.

35. Soares AV, Marcelino E, Maia KC, Borges Junior NG. Relation between functional mobility and dynapenia in institutionalized frail elderly. Einstein. 2017;15(3):278-82. 